\title{
Probing the cerium stable isotopic dynamics of terrestrial and extraterrestrial rocks
}

\author{
HAMED POURKHORSANDI ${ }^{1}$, VINCIANE DEBAILLE ${ }^{2}$, \\ JEROEN DE JONG ${ }^{3}$, ROSALIND ARMYTAGE ${ }^{4}$ AND \\ SOPHIE DECRÉE ${ }^{5}$ \\ ${ }^{1}$ Université Libre de Bruxelles (ULB) \\ ${ }^{2}$ Université Libre de Bruxelles \\ ${ }^{3}$ Université Libre de Bruxelles, DSTE, CP160/02 \\ ${ }^{4}$ Jacobs/NASA \\ ${ }^{5}$ Royal Belgian Institute of Natural Sciences \\ Presenting Author: hpkhorsandi@gmail.com
}

Probing the cerium stable isotopic dynamics of terrestrial and extraterrestrial rocks

Hamed Pourkhorsandi ${ }^{\mathrm{a}}$, Vinciane Debaille ${ }^{\mathrm{a}}$, Jeroen de Jong ${ }^{\mathrm{a}}$, Rosalind M.G. Armytage ${ }^{\mathrm{a}, \mathrm{b}}$, and Sophie Decrée

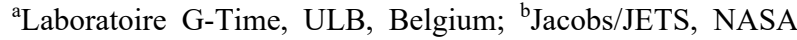
JSC, USA; ${ }^{\circ}$ RBINS, Belgium

E-mail: hamed.pourkhorsandi@ulb.ac.be

The systematics of REE and their radiogenic isotopes are among the main sources of information about the age, origin and formation of terrestrial and extraterrestrial rocks and their parent bodies [1]. Cerium is the most abundant REE. It has four main stable isotopes and the focus so far has been on ${ }^{138} \mathrm{Ce}$, a $\beta$-decay product of ${ }^{138} \mathrm{La}$ [2]. Despite their higher abundance, very little data exist on the distribution of stable ${ }^{140,142} \mathrm{Ce}$ (calculated as $\left.{ }^{142} \delta \mathrm{Ce}\right)$ in the solar system [3-5].

This study aims to (i) investigate the relationship between $\mathrm{Ce}$ elemental abundance with ${ }^{142} \delta \mathrm{Ce}$, (ii) characterize the effects of magmatic petrogenesis and thermal metamorphism on ${ }^{142} \delta \mathrm{Ce}$, and (iii) report the ${ }^{142} \delta \mathrm{Ce}$ composition of the inner solar nebula, based on the analysis of terrestrial rocks and ordinary and enstatite chondrites.

Analytical methodology is described in [6]. ${ }^{142} \delta \mathrm{Ce}$ data of terrestrial igneous reference materials show a relatively homogenous composition between different materials. This indicates lack of magmatic fractionation and/or Ce concentration effects on ${ }^{142} \delta \mathrm{Ce}$ composition. On the other hand, REE ore samples tend to show slightly lighter average ${ }^{142} \delta \mathrm{Ce}$ composition than the common igneous rocks and will require more scrutiny.

Our selected chondritic meteorites cover a range of solar nebula conditions, from highly reduced $\mathrm{EH}$ to highly oxidized LL, and encompassing all petrologic types from 3 to 6 . Our ${ }^{142} \delta$ Ce data show a relatively homogeneous composition between the average value of chondrites and terrestrial igneous samples, except some having lighter or heavier ${ }^{142} \delta \mathrm{Ce}$ compositions without any relationship with their chemical or petrologic types. These observations imply lack of ${ }^{140,142} \mathrm{Ce}$ fractionation during thermal metamorphism, $f \mathrm{O}_{2}$ difference, and between these chondrites and analysed terrestrial samples.

References: [1] DePaolo (1998) Neodymium Isotopic Geochemistry, 261pp. [2] Bellot+ (2015) GCA 168, 261-279. [3] Nakada+ (2013) GCA, 103, 49-62. [4] Nakada+ (2016) GCA, 